\title{
SANTOS, JARDINS DA ORLA - REFERÊNCIA URBANA PARA A COMUNIDADE
}

\section{Ana Kalassa El Banat}

Mestre em artes pela Unicamp, professora de Estética e História da Arte e Arquitetura da FAUUSP - Universidade Santa Cecília - Santos/SP

\section{Luiz Antonio de Paula Nunes}

Arquiteto, mestrando em Estruturas Ambientais Urbanas pela FAUUSP, professor de História e Teoria da Arquitetura e do Urbanismo da FAU Universidade Santa Cecília - Santos/SP

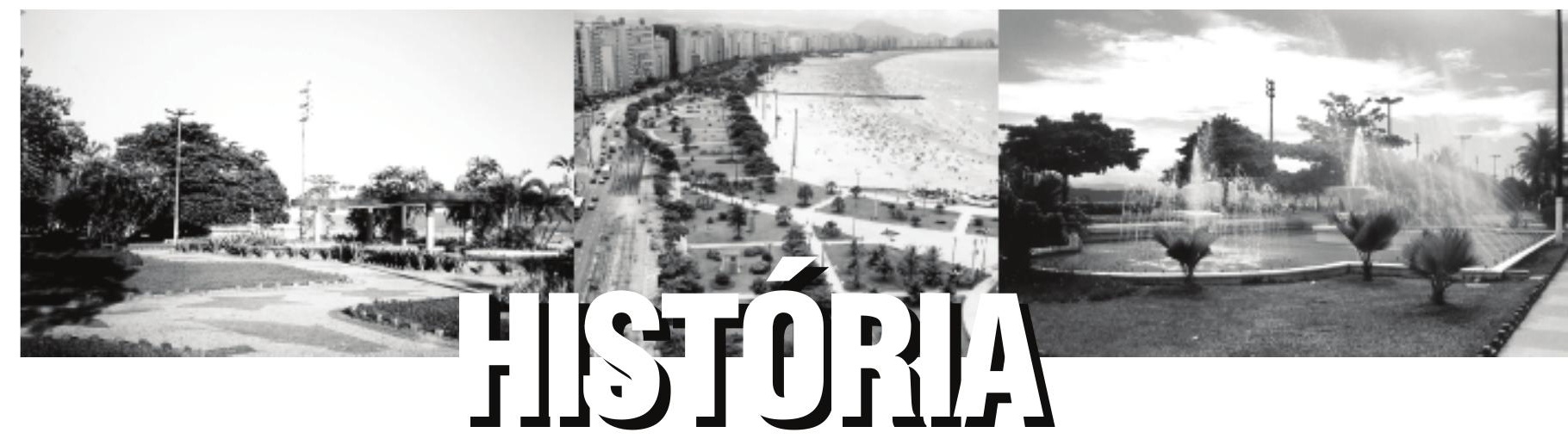




\section{RESUMO}

Este trabalho faz parte do Projeto Portocidade, da Universidade Santa Cecília, uma reflexão sobre a história do desenvolvimento de Santos e uma análise sobre suas perspectivas futuras. A área correspondente aos jardins da orla de Santos, um arco com cerca de $6 \mathrm{~km}$ de extensão e uma largura de algumas dezenas de metros, foi objeto de disputas entre os proprietários dos terrenos fronteiriços à praia e o poder público, durante as primeiras décadas do século 20, até que, a partir dos anos 30 , teve início a construção de gramados sobre a areia. Na década de 50 a relação que se estabeleceu entre a praia e as edificações que surgiram ao longo da orla, e o aumento da ocupação dessa parte da cidade promoveram mudanças importantes, incorporando definitivamente o jardim à paisagem santista.

A partir dos anos 60, a forma de ocupação do jardim e sua caracterização passaram a ser dominantes no debate da comunidade, transformando os jardins da orla na mais marcante referência urbana de Santos. A alteração dos programas de necessidades, das funções e da própria concepção de paisagem, associada a uma crescente importância dada ao transporte individual, geraram conflitos que vêm definindo a maneira como a comunidade vê esse equipamento.

\section{ABSTRACT}

This work is part of the Santa Cecilia University's Project Portocidade, a reflection about the history of the Santos development and an analysis of your future perspective. The area corresponding to the gardens of Santos border, an arch with about $6 \mathrm{Km}$ of extension and a width of some dozens meters, was object of disputes among the proprietors of the frontier lands to the beach and the public power, during the first decades of the century 20 , until that, starting from the thirties, had beginning the construction of lawns on the sand. In 50's the relationship that became established among the beach and the constructions that appeared along the border, and the increase of the occupation of that part of the city, defined the current plan, incorporating the garden definitively to the landscape from Santos. Starting from the sixties the form of occupation of the garden, and your characterization, became dominant in the community's debate, transforming the border's gardens in the most outstanding urban reference of Santos. The alteration of the programs of needs, functions, and the landscape conception, associated to a growing importance given to the individual transport, generated conflicts defining the way as the community sees that equipment. 


\section{SANTOS, JARDINS DA ORLA - REFERÊNCIA URBANA PARA A COMUNIDADE}

\section{O Plano de Saturnino Brito e a Disputa Pelo Domínio da Área}

A ocupação da cidade de Santos remonta à primeira metade do século 16, com a tentativa de se implantar na região a cultura açucareira associada ao potencial de entreposto comercial. $\bigcirc$ insucesso dessa empreitada deixou Santos à margem dos ciclos econômicos pelos quais o Brasil atravessou até o final do século 18 e a cidade manteve suas características coloniais até o século 19, ocupando apenas a área onde hoje se localiza o centro. A praia era o porto, formado por pontes precárias de madeira que permitiam o acesso de cargas e descargas aos trapiches. Uma vez que o navio não podia chegar à cidade, então a cidade chegava ao navio, sem delimitar territórios, em simbiose.

O panorama econômico nacional se modificou com o ciclo agroexportador do café, que propiciou a implantação em Santos da ferrovia e do porto organizado que, por sua vez, em parceria com a cidade, vincularam o desenvolvimento da região à cultura cafeeira. Santos passou a se destacar no cenário nacional e internacional por ser a porta de saída dessa produção e a porta de entrada da imigração, que alterou o perfil populacional do estado, e exigiu que a cidade se preparasse para novos tempos.

A ocupação da região da orla, ou praia da Barra, no final do século 19, era rarefeita, mas mesmo assim, em 1896, um grande número de requerimentos de particulares, solicitando o aforamento dos terrenos fronteiros às suas propriedades, foi encaminhado pelo governo federal para apreciação da Câmara Municipal de Santos. A Câmara rejeitou a cessão dessas áreas, com a concordância do governo do estado, visando a execução de obras de saneamento. A esfera federal se reservou o direito sobre os terrenos fronteiros ao canal do porto para construção desse importante equipamento, mas a disputa prosseguiu em relação aos terrenos da praia da Barra. 
Em 1896 a Câmara Municipal elaborou uma planta da cidade. $\bigcirc$ Plano Geral e Ruas Novas, proposto pela Lei n. 94 de 15/03/1897, era uma malha ortogonal intercalando praças com exatamente as mesmas dimensões das quadras, em desenho monótono e sem preocupação com o sistema viário ou os pequenos córregos que cortavam a cidade ou ainda com o desenho arqueado da praia da Barra.

Santos passou por transformações radicais no quadro urbano geral, destacando-se o Plano de Saneamento do engenheiro Saturnino de Brito, de 1905, que fez uma revisão na proposta da Câmara estabelecendo um novo desenho inspirado nos preceitos sanitários e nas qualidades estéticas defendidas por Camillo Sitte. Santos se preparava para ser uma cidade saneada.

Seu plano possuía, no dizer de Monteiro de Andrade, uma "modernidade européia", pois, enquanto saneava, realizava também o embelezamento da cidade em um mesmo conjunto de reformas espaciais, marcando de modo decisivo sua estrutura urbana até os dias atuais. Aproximou a "cidade" da então distante "Barra", a praia aberta para o mar, baía de Santos, com a construção dos canais de drenagem, cruzados por pontes, ladeados por avenidas arborizadas articuladas com praças, cortando o esquema ortogonal das vias. Santos, que então possuía um pequeno passeio público, na atual praça dos Andradas, hoje desaparecido, deveria ter também uma "avenida-parque" da Barra, com jardins, equipamentos para atividades sociais e campos esportivos.

A área correspondente aos jardins da praia de Santos foi objeto de uma longa disputa entre os particulares, que pretendiam seu aforamento, e o poder público municipal, que a considerava de há muito como logradouro público. "A questão não é nova, toda a gente o sabe, o que, porém, se sabe menos, é que já há diversos anos vem a municipalidade cuidando ativamente de lhe dar uma solução definitiva e de conformidade com os interesses gerais de nossa terra. As praias, as nossas belas e encantadoras praias, são incontestável e evidentemente, logradouros públicos desde há muito tempo, e nunca houve a respeito, a menor dúvida." (Joaquim Montenegro)'

Nessa época os "troles" ligavam Santos a São Vicente com seu trajeto passando pela orla e o Hotel Internacional, localizado na areia da

(1) $\bigcirc$ aforamento de terrenos de marinha na praia da Barra. A Tribuna, 08 mar. 1921, p. 3. 
praia do bairro do José Menino, prenunciava o turismo e a recreação como uma importante alternativa ao desenvolvimento da cidade.

Em 1913 já era possível perceber a rápida valorização por que passariam os terrenos próximos do mar, acarretando novas solicitações de aforamentos de trechos da praia por particulares. "Ainda há bem pouco tempo a Câmara Municipal viu que, dentre o aluvião de pretendentes a tais terrenos nenhum só se propunha a criar estabelecimentos que fossem úteis à indústria e mesmo ao comércio. Era somente a especulação que preponderava. ${ }^{\prime 2}$ A resposta da municipalidade foi a solicitação de aforamento de toda a faixa lindeira à praia da Barra ao município, por meio de requerimento ao Ministério da Fazenda, datado de 6 de julho de 1918, instruído por plantas e memoriais justificativos.

Não obstante todo esse trabalho, nova batalha entre o poder público e os particulares ocorreu durante o ano de 1921. Essa disputa se deu, principalmente, pelo fato de não existirem os melhoramentos que caracterizassem a efetiva urbanização da área. A polêmica gerada pelo desejo de loteadores teve suas primeiras conseqüências na sociedade santista, que protestou contra a intenção de criar lotes entre a avenida já existente, ainda que de areia, e a faixa da praia, onde o rasteiro jundu era a planta que dominava o local.

A questão mobilizou também intelectuais, como o poeta Vicente de Carvalho que, com o prefeito Joaquim Montenegro, organizou um abaixo-assinado para ser enviado a Epitácio Pessoa, presidente àquela época, solicitando que coubesse à prefeitura determinar a forma de urbanização do local. A prefeitura fez um protesto judicial e o prefeito foi pessoalmente ao Rio de Janeiro para se entender sobre o assunto com o diretor do Patrimônio Nacional e o ministro da Fazenda.

A edição do jornal A Tribuna, de 5 de janeiro de 1922, trouxe em sua primeira página a manchete: "Uma vitória da cidade - Resolve-se em favor da prefeitura local a velha questão dos terrenos da Marinha". $\bigcirc$ ministro da Fazenda havia concedido o aforamento dos terrenos na área urbana, com condições de estabelecimento de servidões e logradouros públicos nas áreas que já não estivessem cedidas à Companhia Docas de Santos. A essa decisão coube recurso e somente em 1934, com a condição de que não fosse explorada comercialmente, é que a causa foi definitivamente ganha. 


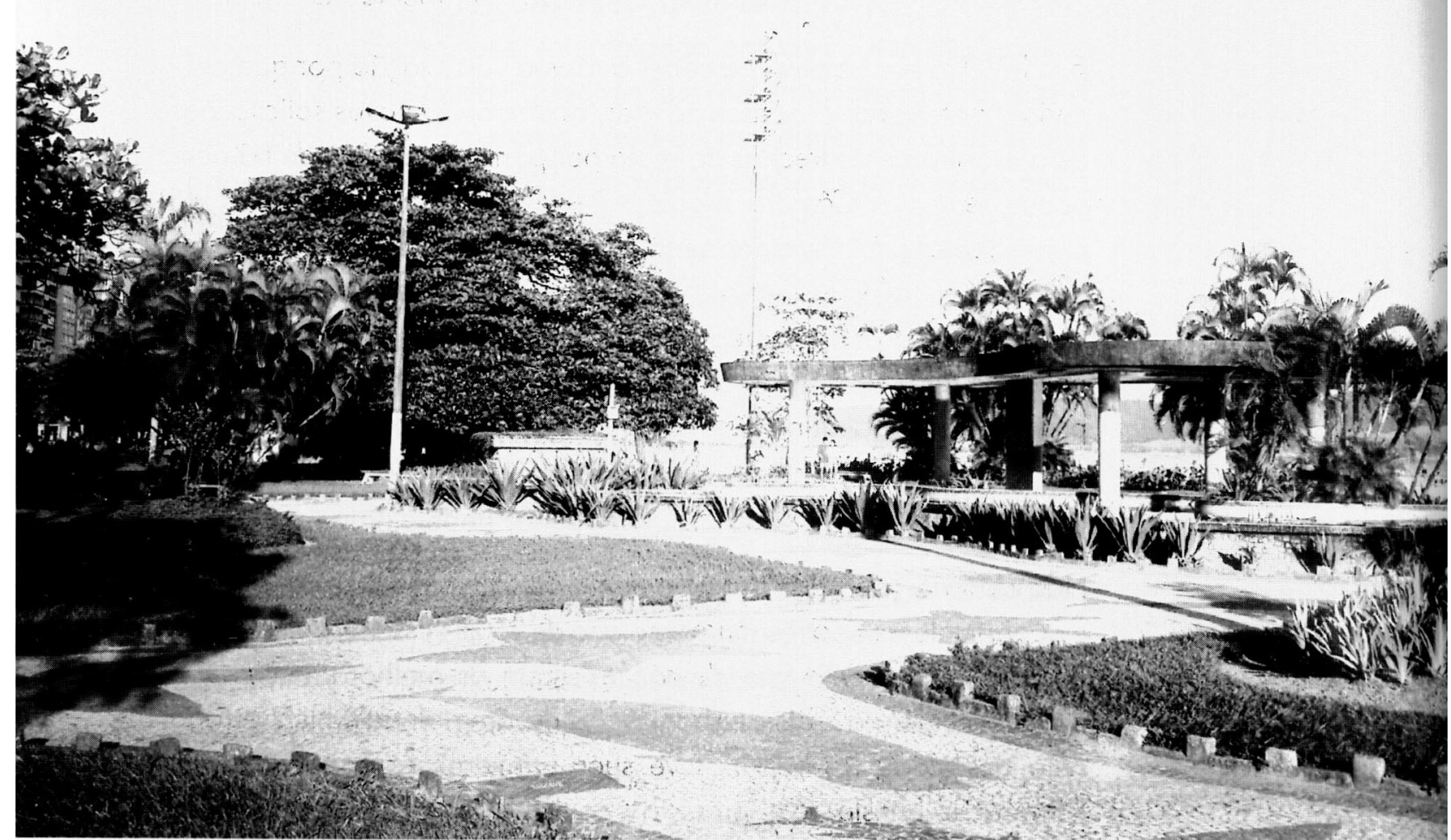

Foto 1 - Jardins da Orla

Crédito: Ana de Castro

\section{Os primeiros melhoramentos}

"Saneada grande zona da cidade, o progresso começou logo de manifestar-se nela; e não mais se deteve. Para os lados da praia da Barra, desde o Boqueirão até o José Menino, zona beneficiada pelo saneamento, a população começou a estender-se, os homens abastados aí construíram edificações de luxo, estabeleceram grandes hotéis, multiplicaram-se as pensões familiares, fundaram-se cassinos. Mas a extensa avenida aberta entre as residências e a praia, era, na época das chuvas, um horrível atoleiro que dificultava o trânsito e as comunicações com a cidade. ${ }^{\prime^{3}}$

Na década de 20 tiveram início as primeiras obras, tímidos calçamentos em paralelepípedos e calçadas em mosaico português que delimitaram os primeiros trechos de um jardim que nascia de forma quase improvisada, especialmente nas áreas fronteiriças aos hotéis que se instalavam, como o Atlântico, o Internacional e o Parque Balneário. Esse momento é particularmente importante para a cidade, na medida em que outros serviços públicos foram implantados, como

(3) Os progressos de Santos - Obras nas praias. A Tribuna, 5 out. 1923. 
a instalação da rede de águas pluviais e a iluminação pública ${ }^{4}$, além das cabines para banho, um coreto, que não mais existe, no Canal 2, e o plantio dos primeiros "chapéus-de-sol" (Terminalia catappa) ${ }^{5}$.

No princípio da década de 30, antes mesmo da decisão final sobre as questões de aforamento, a prefeitura iniciou a urbanização da área entre a avenida e a praia, optando por um extenso gramado, em função do baixo custo de implantação, cujos primeiros desenhos, para o trecho entre os canais 2 e 3 , onde existiam os hotéis mais importantes, são atribuídos ao engenheiro Paulo Veiga ${ }^{6}$.

Essa década foi marcada por uma sucessão de prefeitos nomeados, principalmente funcionários municipais. Na construção dos jardins destacou-se a gestão do engenheiro Aristides Bastos Machado. Participaram dessa primeira fase de construção dos jardins da orla, que terminou em 1939 na gestão de Cyro de Athayde Carneiro, Carlos Lang $^{7}$, que era o chefe da Divisão de Plano e Cadastro, a qual se ocupava de melhoramentos em geral (arruamentos, nivelamentos, calçamentos, jardins, galerias de águas pluviais), os engenheiros Adalberto Moura Ribeiro e Hugo Benedito de Oliveira, além do jardineiro responsável, Carlos Colaris, do Horto Florestal de São Paulo ${ }^{8}$.

Esses jardins apresentavam desenhos simétricos na distribuição das árvores, caminhos retilíneos que levavam à praia, além de esparsos bancos, luminárias e alguns postos salva-vidas. Ainda assim, essa iniciativa teve tanta repercussão que Cyro de Athayde Carneiro afirmava em sua propaganda política, quando candidato a deputado estadual pelo Partido Republicano", ter realizado "notável obra no setor dos melhoramentos públicos... ajardinamento da praia entre o Boqueirão e a Ponta da Praia,..."

Os jardins, aparentemente, sofriam com seu uso desordenado, o que motivou a municipalidade a intervir, executando obras como o calçamento ao lado dos trilhos do bonde nos anos 40, e a construção de fontes e do Aquário Municipal, último empreendimento turístico executado pela prefeitura de Santos. "Jogos de futebol e piqueniques nos extensos gramados dos jardins eram comuns no início dos anos 40. Com o projeto paisagístico ainda indeterminado, muitas áreas já

(4) Os progressos de Santos. A Tribuna, 17 out. 1923, p. 2.

(5) Chapéus-de-sol, a imagem símbolo. A Tribuna, 27 ago. 1988.

(6) Todo cuidado é pouco para cuidar dos jardins. A Tribuna, 26 jan. 1996, p. 17.

(7) Paulistano nascido a 02/03/1909, engenheiro-arquiteto pela Politécnica em 1935. (Ficher, 1989).

(8) Todo cuidado é pouco para cuidar dos jardins. A Tribuna, 26 jan. 1996, p. 17.

(9) Nas eleições de janeiro de 1951. 
estavam seriamente deterioradas... A transformação da praia como área de grande concentração urbana começou nos anos 40, e na década seguinte teria início a especulação imobiliária, os jardins sobreviveram a tudo isso."10

O panorama das edificações existentes na orla, constituídas por chácaras de propriedade de comerciantes ligados ao café, alterou-se com a democratização do lazer que passou a ocorrer em meados do século 20. A via Anchieta, nova "superestrada" inaugurada em 1947, estimulava o desejo de se obter na praia um "refúgio". O mar, que era visto apenas por suas propriedades terapêuticas, era agora também parte desse lazer. A economia se movimentava e vários prédios de apartamentos foram lançados, tendo como "mote" o descanso, que era usado nas propagandas: "Graças à Via Anchieta que encurtou a distância entre o litoral e São Paulo, os paulistanos podem gozar os encantos da vida a beira-mar... A praia do Gonzaga, principalmente, está se tornando uma nova Copacabana..."11.

Menotti del Picchia descreveu a Santos da década de 50 de uma maneira toda peculiar: "Minha última estada na praia mostrou-me uma Santos em plena reação. O paulista já compreendeu o alcance da oxigenização do seu organismo após o desgaste da semana. O sol marinheiro, o vento do largo, o exercício nas ondas e nas areias valem tanto para um corpo como para um automóvel a sua lavagem e lubrificação. O camarada volta novo tal qual o cristal lascado depois de reimerso na água-mãe.

O que há de pitoresco na Santos de hoje é que a vida balneária não é mais apenas granfina: o pequeno burguês e o proletário já compreenderam que a vida pertence igualmente a todos, assim como a beleza, a saúde, o descanso e o sol. Certas zonas dão negro e mulato que parece estarmos em Tanganika ou no Sudão. Outras faz brotar sírios da areia como se estivéssemos no Marrocos. Italiano, isso reponta em toda parte. Português é nativo da terra de Brás Cubas. Pelo que se vê, a praia santista é um colorido museu de raças onde, como em todo o agrupamento urbano, acaba dominando o judeu. Judeus de carne branca como requeijão e pêlos loiros - os polacos e

(10) Chapéus-de-sol, a imagem símbolo. A Tribuna, 27 ago. 1988.

(11) Jornal A Tribuna, 24 mar. 47, p. 5. 
os romenos - arrastando as gordas esposas pela mão e rumando para as ondas falando 'yedich' ou recitando um fragmento da Torá. Santos, atração máxima das populações paulistas, amanhã será pequena para abrigar o mundaréu de turistas que ali irão gozar o 'weekend'... $^{12 \prime \prime}$

Prestes Maia propôs, entre 1947 e 1950, o Plano Regional de Santos, centrado na questão portuária e no sistema viário. Esse plano serviu de base para o Plano Regulador da Cidade de Santos, de 1951, um dos primeiros documentos do planejamento urbano local. Em seu plano, quanto aos aspectos de lazer, Prestes Maia previa a implantação de equipamentos esportivos e sociais, para crianças e adultos "proletários" nos bairros, e balneários com piscinas cobertas nas praias do Boqueirão, Gonzaga e Ponta da Praia, com a utilização de parte dos jardins.

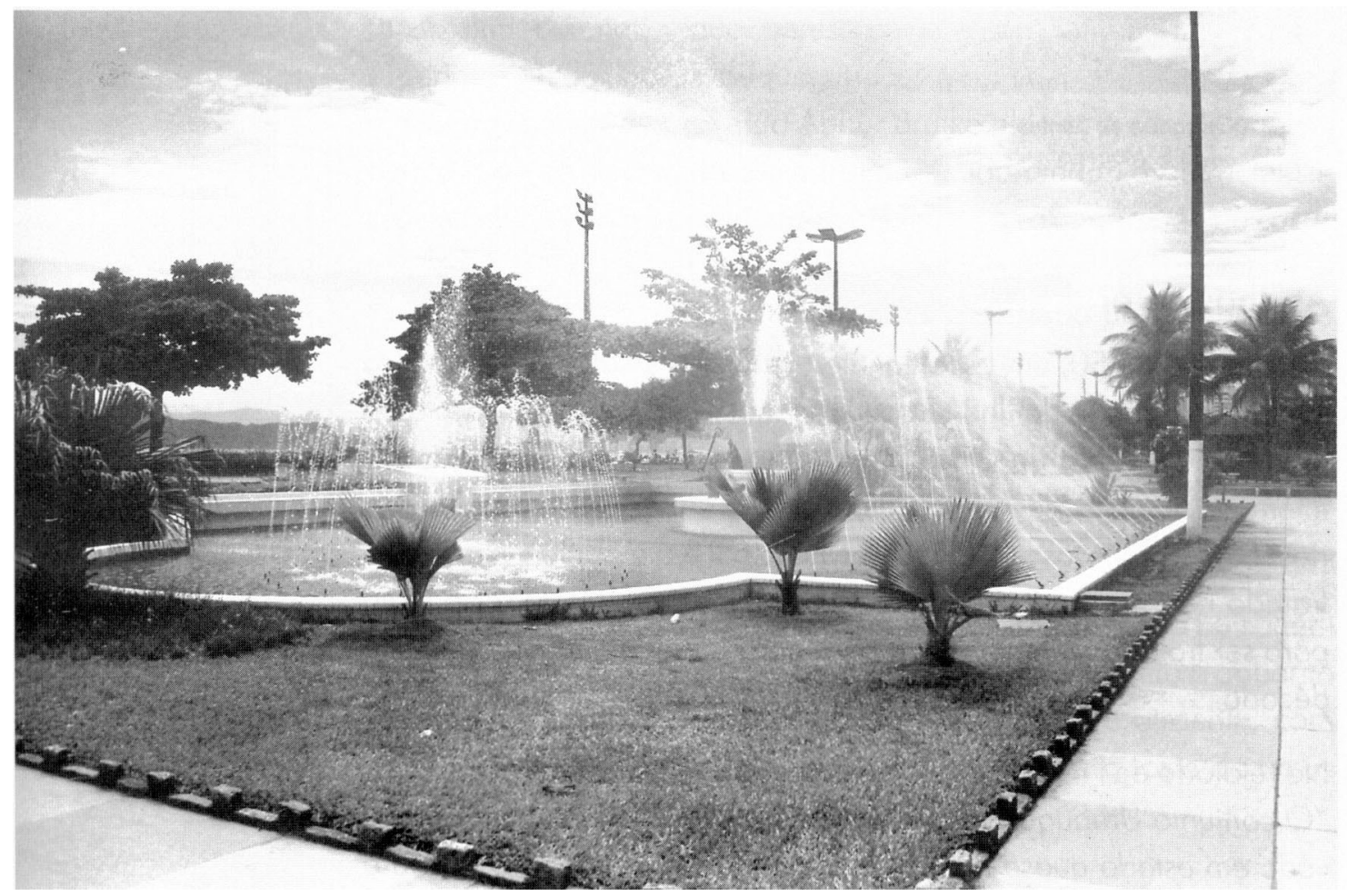

Foto 2 - Jardins da Orla

Crédito: Ana de Castro

(12) Extraído de "Santos e Prestes Maia", publicado por A Gazeta de São Paulo, 16 fev. 1949. 


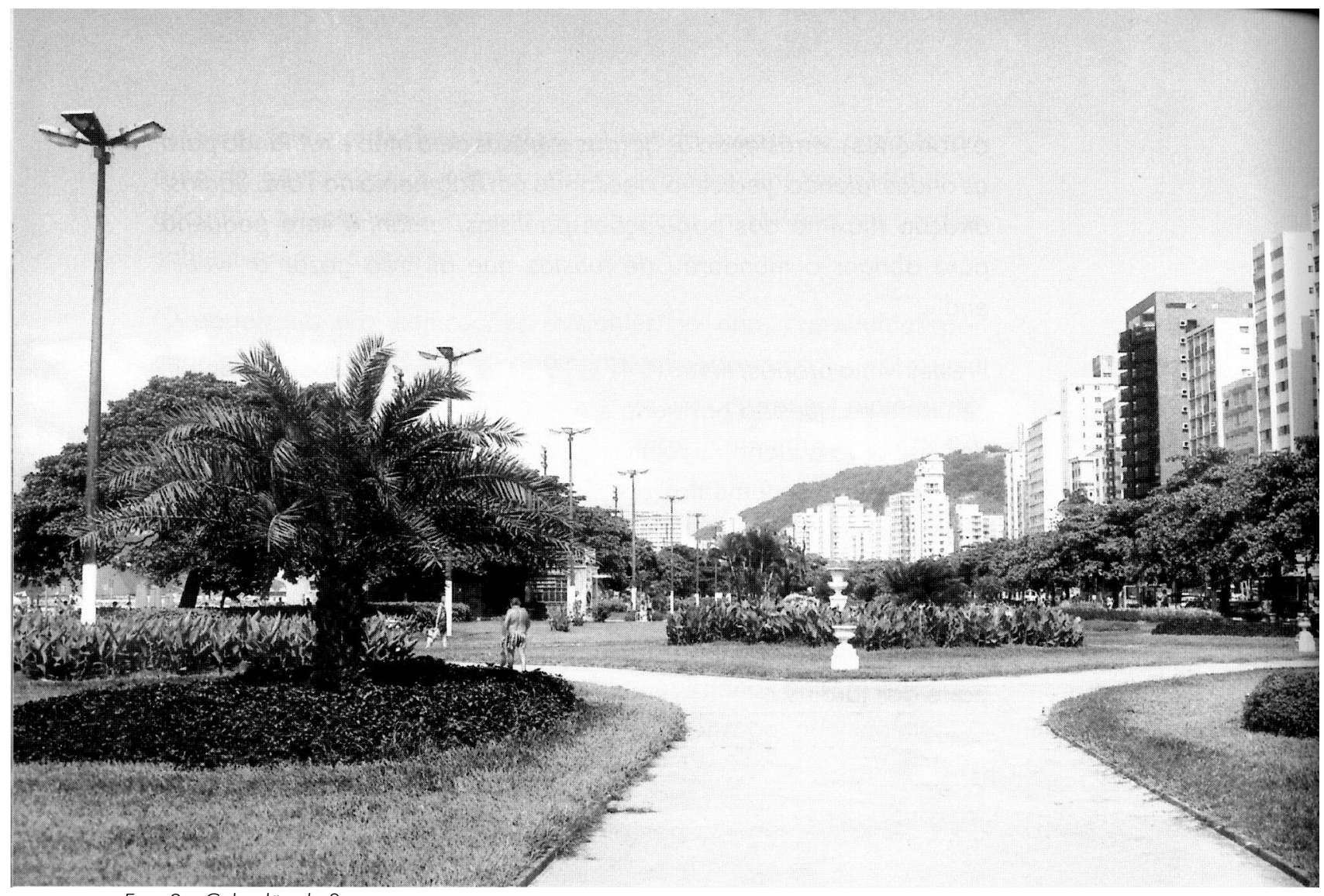

Foto 3 - Calçadão de Santos

Crédito: Silvio S. Macedo

\section{As ilhas da orla}

Nos anos 40 e 50, um aspecto interessante a ressaltar é a polêmica sobre a ocupação da llha Urubuqueçaba ${ }^{13}$. Havia uma proposta do escritório de Plínio de Queirós para sua ocupação que, dada sua interferência na paisagem, dividia a cidade entre favoráveis e contrários. Santos não possuía Câmara Municipal e o assunto vinha sendo tratado na esfera estadual que, por sua vez, preferiu deixar o tema para ser tratado pela futura Câmara a ser instalada no final daquela década.

No relatório de Prestes Maia o assunto foi tratado da seguinte forma: "O conjunto Urubuqueçaba-Internacional, não podendo ser conservado em estado quase natural, poderá receber construção sujeita a aprovação especial. A língua de areia submersível, que a liga, não deve receber construção de modo algum..." Já no relatório de Carlos

(13) Pequena ilha marítima próxima à praia, na divisa entre Santos e São Vicente; sua ocupação e do entorno sempre foi objeto de interesse particular até os dias de hoje, mas ela ainda se mantém intacta. 
Lang: "O plano de urbanização da llha Urubuqueçaba, indicado pelo Engenheiro Prestes Maia, já foi por nós estudado, de comum acordo com os proprietários da referida ilha e terrenos adjacentes, estando o referido plano na sua fase final de aprovação."

A cidade participou ativamente dessa discussão, por meio de jornais e de reuniões na Associação dos Engenheiros, no Rotary Club e na Comissão do Plano da Cidade ${ }^{14}$, que refletia esse debate. $O$ engenheiro Hernani Botto de Barros, visando a preservação do ambiente, afirmava que o projeto se tratava de "uma mutilação criminosa de paisagem magnífica", mas outros eram favoráveis, como o presidente da comissão, o vereador Antonio Alves Arantes, para quem os primeiros eram "poetas, sentimentais e românticos", e outros ainda, como Aníbal Martins Clemente ${ }^{15}$, que buscavam uma conciliação ${ }^{16}$, propondo que a ocupação observasse "os princípios da Carta de Atenas".

Em contraponto, na mesma época, foi aprovado um empreendimento na llha Porchat", que apresentava qualidades inegavelmente superiores ao da llha Urubuqueçaba. $O$ empreendimento estava sob a direção técnica de Oswaldo Arthur Bratke e deveria ser, de acordo com o texto do decreto que o aprovou, "subordinado às características de cidade-jardim, destinando-se os terrenos à construção de casas residenciais e de prédios de apartamento"18 . "... A llha Porchat se transformará no centro de atração mais procurado pelos turistas de todas as partes do mundo. As suas belezas naturais empolgam o mais displicente observador, e essas belezas naturais realçadas por trabaIhos de engenharia de envergadura apresentarão um conjunto harmonioso que fará as delícias de todos que aqui venham para repousar ou recrear o espírito". (Oswaldo Bratke)

A llha Porchat de hoje não é o previsto por Bratke, pois sua paisagem foi descaracterizada por edifícios que superaram em muito o gabarito máximo permitido no projeto original, mas ainda é atraente, com edifícios isolados lembrando elementos soltos na proposta do urba-

(14) Essa comissão, instituída em 1948, tornou-se marco na discussão da questão urbanística.

(15) Português radicado no Brasil, engenheiro-arquiteto pela Escola Politécnica da USP em 1940.

(16) Parte do debate foi publicado na edição de 4 jun. 1950 de A Tribuna.

(17) Ilha marítima em São Vicente, voltada para a baía de Santos, cuja ligação com a cidade foi assoreada, alterando o regime de deposição de areia nas demais praias do município.

(18) Decreto Municipal n. 24/47.

(19) Jornal A Tribuna. Santos, 16 fev. 1950, p. 3. 
nismo modernista. Já a llha Urubuqueçaba não se concretizou como obra, o que certamente sacrificaria a natureza pelo maciço de prédios ocultando seu relevo, e manteve seu perfil e sua composição na orla marítima de Santos, compondo com os atuais jardins.

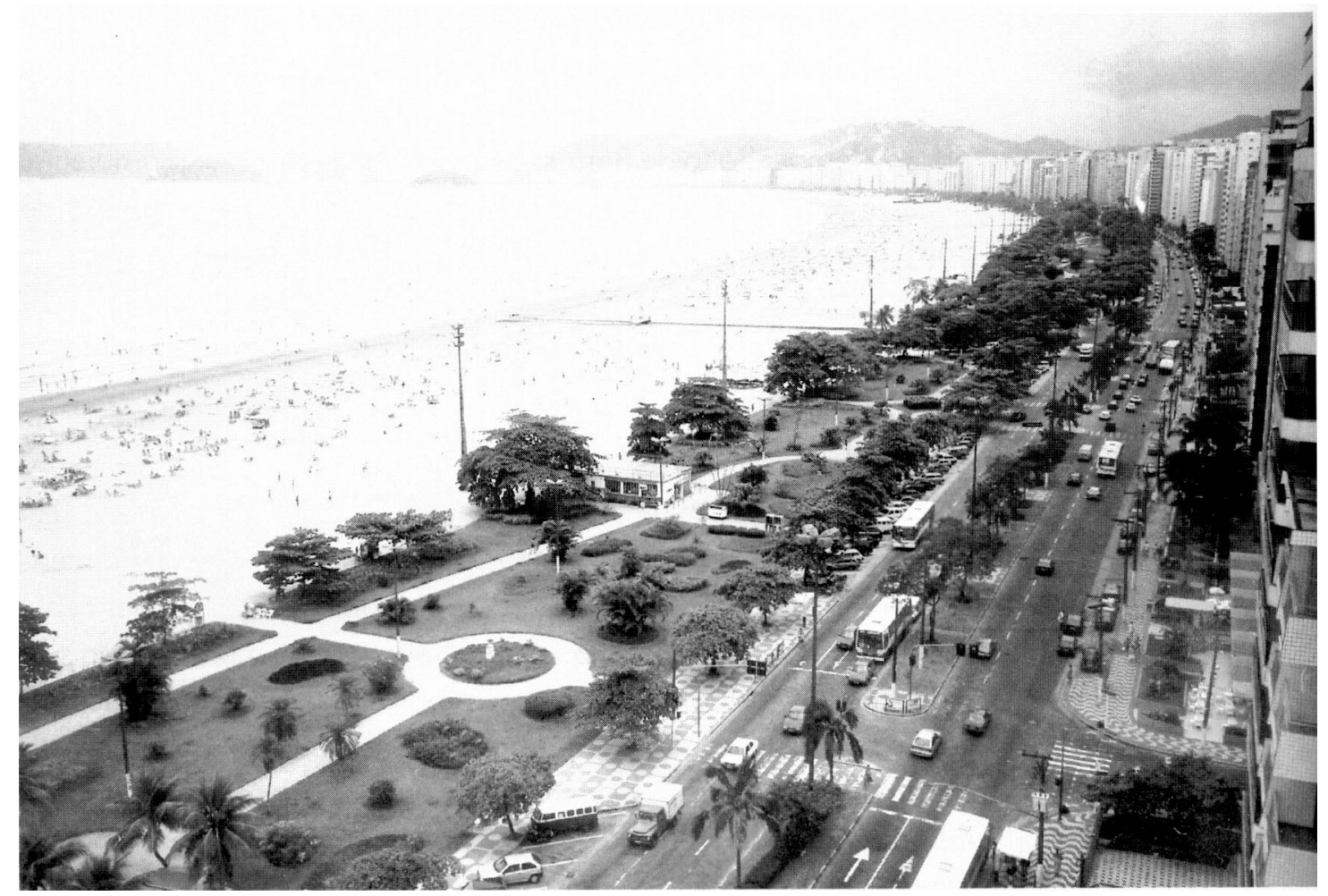

Foto 4 - Calçadão de Santos

Crédito: Francine Gramacho Sakata

\section{A conformação dos jardins}

Antonio Feliciano foi o prefeito (1953/1957) que se destacou especialmente pelas obras de embelezamento na avenida da Praia. Sua proposta de duplicação da avenida da Praia gerou polêmica, surgindo três hipóteses para sua realização: 1. demolição de um pedaço do jardim ao lado da linha do bonde para construção da nova pista, separada por um canteiro central; 2. construção da segunda pista na praia, deixando o jardim como um grande canteiro central; 3. retirada das linhas de bonde. A cidade discutiu o assunto pela imprensa, e apesar das controvérsias foi realizada sacrificando parte dos jardins. A partir dessa obra os jardins se estenderam para a Ponta da Praia, mesmo vetor de crescimento da cidade, e passaram definitivamente, com os canais, a caracterizar seu desenho urbano.

A década de 60 foi o marco para a definição do traçado característico dos jardins da orla, que passaram, então, a caracterizar-se 
como um parque urbano. Em 1957, o ex-vereador e engenheiro Silvio Fernandes Lopes transformou-se no mais jovem prefeito de Santos (1957/1961 e 1964/1968). "... Priorizando a necessidade de concluir as obras da gestão anterior, como na avenida da praia, por exemplo, que havia sido alargada, nós reformamos os jardins para que a cidade pudesse ter uma orla bonita e agradável aos santistas e a recomposição da avenida Conselheiro Nébias, ligando a praia ao centro. ... Através de uma luta política muito grande,... conseguimos a área necessária para implantarmos o horto de Santos, na Zona Noroeste, que permitiu o plantio de várias espécies na cidade. Para isso foi fundamental o papel do agrônomo Armando Martins Clemente..." 20

Armando Martins Clemente teria baseado seu projeto em estudos que levaram em consideração três aspectos da praia de Santos: o clima agressivo, o vento dominante sul, e ser depositária de areia, o que permitiria a formação de pequenas dunas. É interessante observar que as espécies escolhidas para comporem o jardim, segundo os aspectos climáticos e o efeito estético pretendido, deveriam evitar a obstrução visual da praia, ao mesmo tempo em que propiciassem um movimento vertical, criando uma verdadeira moldura vegetal para o horizonte marítimo ${ }^{21}$.

Esse engenheiro agrônomo foi o responsável pela conformação paisagística dos jardins como se apresentam até os dias de hoje. A partir de seu projeto, não ocorreram grandes transformações, apesar das tentativas que se seguiram nas décadas posteriores, e a manutenção dos jardins passou a ser a atividade principal do poder público. Ocorreram alterações pontuais e inclusão de outros vegetais substituindo, devido a problemas com roedores, algumas espécies anteriormente implantadas com o objetivo de disciplinar o uso dos jardins. A construção de monumentos e a implantação de bustos passou a ser também outra forma de intervenção constante nos jardins.

"... Num encontro de dois de seus passeios de cimento, o busto de um poeta. E depois, numa quina de canteiro, o bronze... a estátua de Saturnino de Brito... um almirante - Tamandaré... um educador - João Otávio... A estátua com Vicente de Carvalho - e as ondas de seu mar - também emprestou uma particularidade ao gramado, às copas dos

(20) Entrevista oferecida por Silvio Fernandes Lopes a Luiz Antonio de Paula Nunes em setembro de 1997.

(21) Chapéus-de-sol, a imagem símbolo. A Tribuna, 27 ago. 1988. 
chapéus-de-sol, às flores dos primitivos jardins. Cada uma dessas lembranças enfeita a praia que o santista gosta de ver ajardinada... o jardim do Boqueirão com a pérgula e o lago... no Gonzaga há a fonte luminosa, ... em Aparecida há a fonte dos Sapos... o Aquário... o Leão de concreto... o relógio de sol..." ${ }^{\prime 22}$. Esses monumentos e outras instalações que foram sendo acrescentadas aos jardins, ainda que discutíveis no seu aspecto estético e na quantidade, também passaram a se fixar na memória coletiva, conformando sua identidade.

\section{Em Discussão os Jardins das Praias}

"... O santista, que já se ufanava de seu quilométrico jardim praiano passou a admirá-lo ainda mais... ele passou a defender o que considerava o mais belo de Santos, os jardins de sua praia. Verdadeiro cartão de visita da cidade..." (Lydia Federici) $^{23}$.

Em tempos de intervenção federal teve início, em 1973, por meio da empresa de economia mista municipal Progresso e Desenvolvimento de Santos S. A. - Prodesan, uma alteração no trecho entre a divisa de São Vicente e o Canal 1, com o alargamento da via, e a implantação de faixas para estacionamento de veículos. As obras prosseguiram, anos mais tarde, no trecho entre os canais 5 e 6, mas a conclusão em toda a extensão da praia sempre dependeu de verbas vinculadas à Empresa Brasileira de Transportes Urbanos - EBTU, subordinada ao Ministério dos Transportes.

Tais obras geraram, desde 1973, uma mobilização encabeçada pelo autodeno-

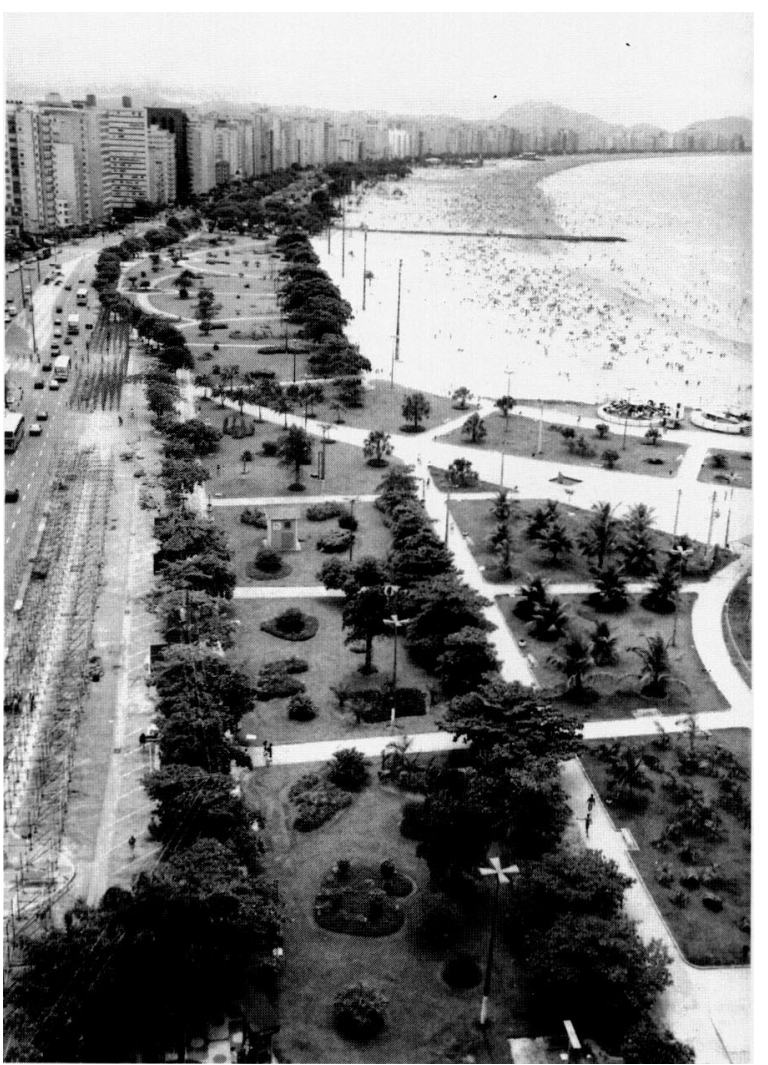

Foto 5 - Orla de Santos

Crédito: Ana de Castro minado Movimento de Arregimentação Feminina - MAF. Este elaborou um abaixo-assinado, conseguindo a interferência do Conselho de Defesa do Patrimônio Histórico, Arqueológico, Arquitetônico e Turístico do Estado de São Paulo -

(22) O jardim João Moreira Salles. A Tribuna, 24 jul. 1982.

(23) A praia de Santos. A Tribuna, 5 set. 1989, p. 24. 
Condephaat. A ação deste órgão, que pediu o detalhamento do projeto, motivou a paralisação da obra, que também incluía a construção de plataformas sobre os canais na faixa dos jardins.

Em seu documento, o MAF afirmava entre outras coisas: "assim como a Torre Eiffel identifica Paris, a Estátua da Liberdade caracteriza Nova York e a 'calçada de mosaico' lembra Copacabana, uma larga e ajardinada praia bem pode ser o símbolo de Santos, porque, praias, pelo mundo, há muitas. Jardins, muito mais. Mas praias, com $6 \mathrm{~km}$ de jardins e ainda, com extensa faixa de areia para ser por todos usufruída, só as de Santos. "24 Exageros à parte, fica caracterizada aqui a crescente importância que os jardins ganharam a ponto de poder identificar a cidade.

Apesar disso, na Câmara Municipal, prosseguiu o debate visando a redução dos jardins para ampliação das faixas de rolamento da avenida da Orla. Fernando Oliva, na época vereador e líder da bancada da Arena, chamava a atenção para a inauguração da rodovia dos Imigrantes, e suas conseqüências sobre o aumento do fluxo de veículos na orla, para justificar sua posição: "Se eu sou o prefeito, abro as pistas nos jardins." 25

Entre as reações às colocações do vereador destaca-se o artigo "A cidade é dos homens": "... E como não é pecado, mesmo porque não ganho nada do povo para dizer besteiras, também vou fazer a minha sugestão; rebentar as avenidas da praia e construir jardins em seus lugares. Os carros que descerem a serra que se danem, pois as cidades e praias foram feitas para as pessoas e não para os veículos. Toda cidade tem seu limite para ceder ao progresso, mesmo que os jardins fossem totalmente destruídos e transformados em pistas e estacionamento, num futuro bem próximo, o espaço ainda seria insuficiente para acomodar todos os automóveis que demandarão às praias." ${ }^{26}$

No início dos anos 80, a obra de alargamento da avenida, então no trecho compreendido entre os canais 4 e 5, prosseguiu com maiores cuidados: "De todo modo, o tradicional jardim da praia não permanecerá intacto. A Prefeitura promete, porém, que o arvoredo existente junto à avenida será inteiramente transplantado a exemplo do trecho concluído entre os canais 5 e 6 e o jardim totalmente recuperado. "27

(24) Praias de Santos. A Tribuna, 23 maio 1973.

(25) Lava-rápido e jardins. Em discussão na Câmara. A Tribuna, 3 ago. 1976.

(26) Max de Sancti. A Tribuna, 8 ago. 1976.

(27) Obras na avenida da praia. A Tribuna, 18 ago. 1981. 
No entanto, a polêmica retornou quando o mesmo vereador Fernando Oliva apresentou requerimento pedindo estudos sobre a possibilidade de alargamento da avenida da Praia sobre os jardins. A imprensa participou ativamente desse episódio com a publicação de uma série de artigos e manifestos em defesa dos jardins, que chegaram a contar com o selo "Diga não à destruição".

Em defesa dos jardins manifestaram-se vereadores como Mantovani Calejon, Manoel Constantino, Noé de Carvalho e Telma de Souza, ecologistas como Ernesto Zwarg, paisagistas como Oswaldo Casasco, e representantes de movimentos populares como Carlos Alberto Mourão, do Movimento de Defesa da Vida, José Carneiro de Oliveira, do Sindicato de Vigias Portuários, além de outras pessoas ouvidas pelo jornal, que promoveu o debate realizado em 25/03/1987, envolvendo setores públicos e privados da comunidade santista ${ }^{28}$. Esta ação resultou no não-alargamento da avenida.

A década de 90 principiou com a discussão sobre a ampliação do antigo Aquário Municipal, prosseguiu com a implantação de pequenas edificações, quiosques para abrigar lanchonetes, em substituição aos trailers de lanches adaptados e permanentemente estacionados na orla da praia usados até então, continuou com posições divergentes sobre o plantio de palmeiras e coqueiros, realizado sem um amplo estudo paisagístico, e terminou com a polêmica sobre a construção de um grande equipamento comercial próximo à llha Urubuqueçaba e a implantação da ciclovia entre os jardins e a praia.

O projeto do novo aquário, de autoria de Paulo Mendes da Rocha, foi engavetado devido à forte oposição de movimentos como o MAF, todos os precários trailers foram retirados, e os quiosques implantados de forma concentrada em determinados pontos, a fim de não prejudicar a paisagem, as palmeiras foram plantadas em apenas um pequeno setor dos jardins, a construção do equipamento comercial foi obstada judicialmente e a implantação da ciclovia tem sua discussão ainda em aberto. $\bigcirc$ projeto da ciclovia, ainda que não interfira drasticamente no desenho dos jardins, tem sido motivo de posições antagônicas e sérias reservas por parte do ministério público: "A areia da praia é intocável, é sagrada." ${ }^{29}$

(28) Artigos publicados por A Tribuna durante todo o mês de março de 1987, inclusive a íntegra do debate.

(29) MP vai acompanhar projeto de ciclovia na orla da praia. A Tribuna, 4 jan. 1997. 


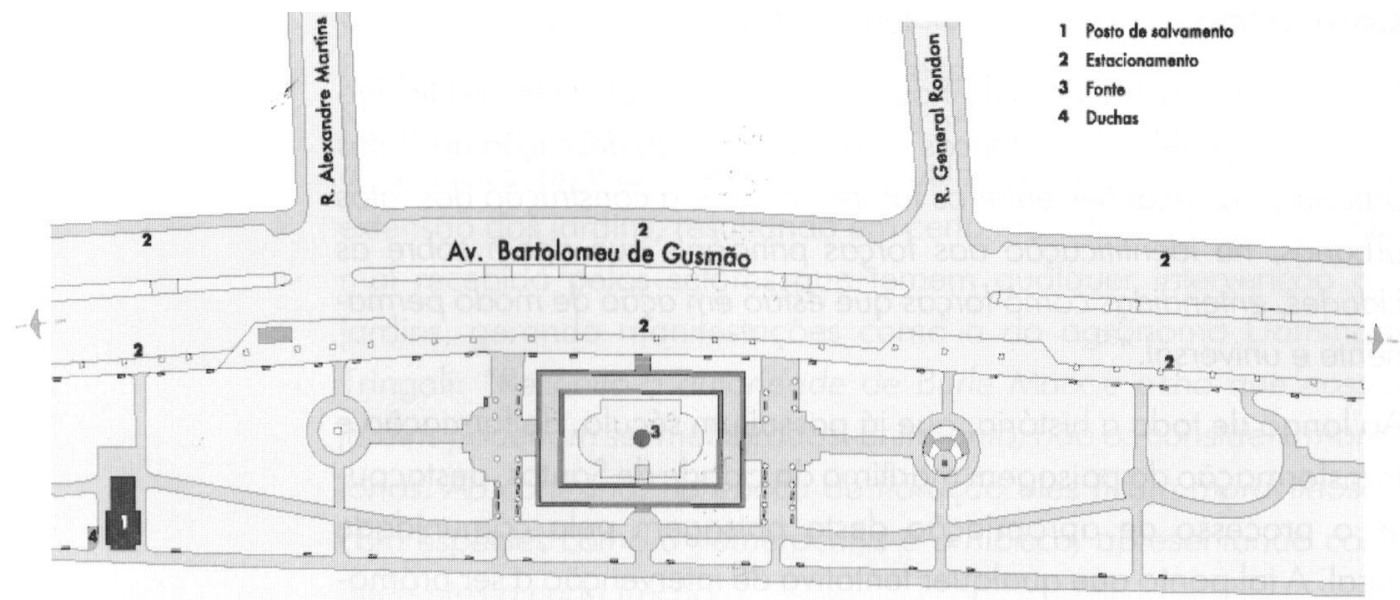

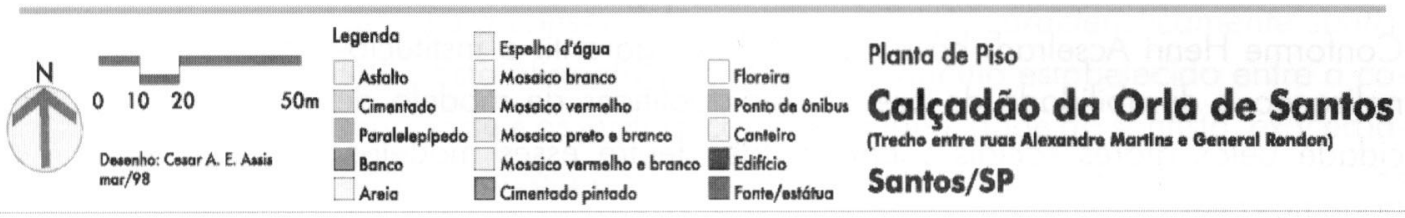

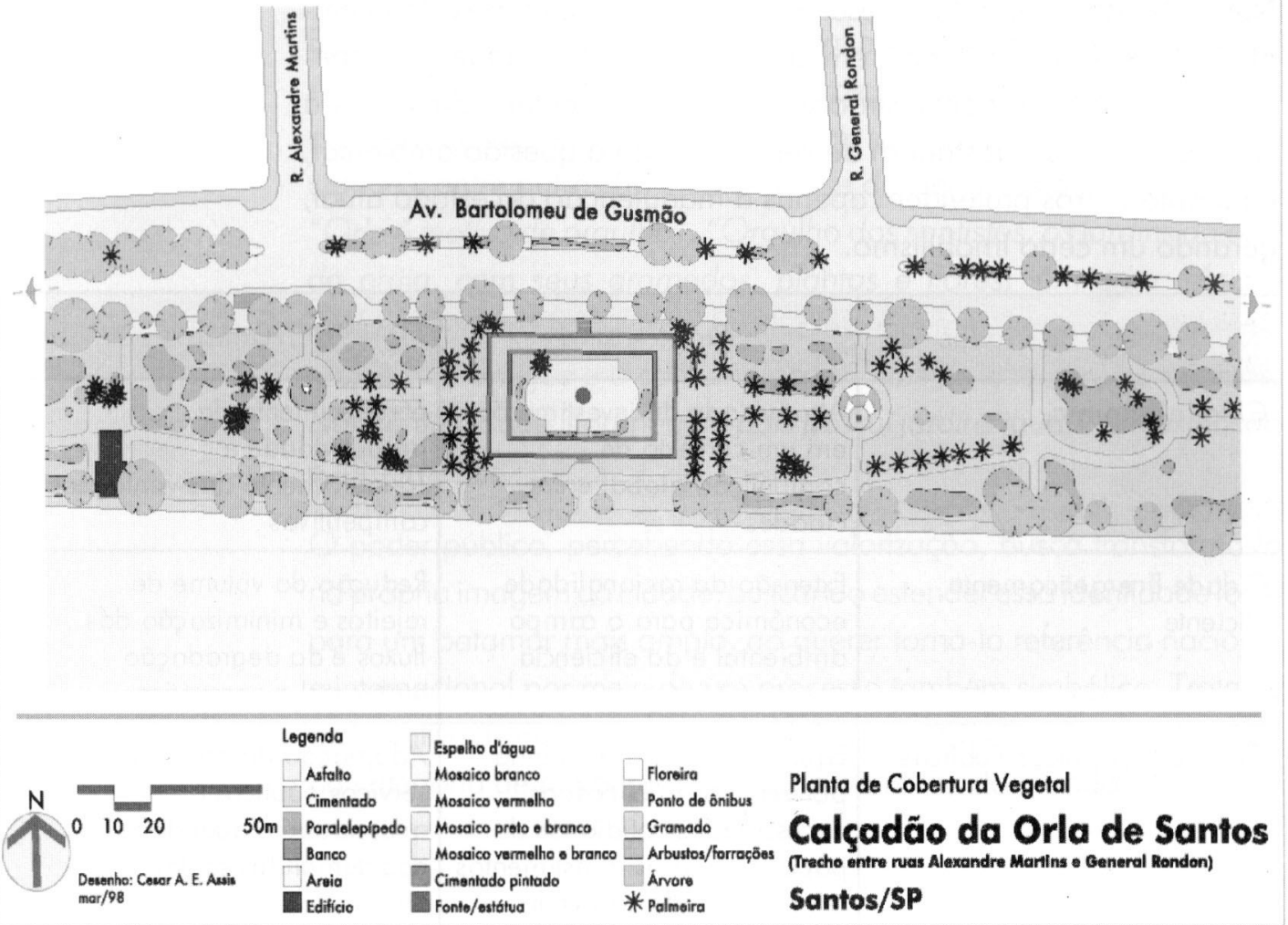

Mapas 1 e 2 - Calçadão da Orla de Santos

Crédito: Cesar A. E. Assis 


\section{Conclusão}

Seguindo os passos de Aldo Rossi, procuramos nos deter "particularmente nos problemas históricos e nos métodos de descrição dos fatos urbanos, nas relações entre os fatores locais e a construção dos fatos urbanos, na identificação das forças principais que agem sobre as cidades, entendidas como forças que estão em ação de modo permanente e universal. ${ }^{\prime 30}$

Ao longo de toda a história, que já possui um século, de formação e transformação da paisagem marítima da cidade de Santos, destacouse o processo de apropriação desta paisagem pela comunidade local. A tal ponto que qualquer tentativa de intervenção a ser promovida, envolvendo os jardins, sem entrarmos na discussão do valor ou da necessidade das mesmas, passou a ser objeto de discórdia, dificultando sua realização. No centro dessa disputa podemos observar vários aspectos.

Conforme Henri Acselrad, há uma luta para garantir a institucionalização e durabilidade de pressupostos políticos de modelo de cidade pelos atores sociais ${ }^{31}$. Em Santos, dentre esses modelos, podemos citar:

Neste antagonismo estão presentes também idéias como o "contemplativo" versus o "utilitário", em que parte da coletividade, em especial empresários e administradores, quer acrescentar novos usos a essa área; alguns gostariam de ver valorizada a questão ambiental, enquanto outros pretendem apenas a manutenção do estado atual, gerando um certo imobilismo.

\begin{tabular}{l|l|l}
\hline \multicolumn{1}{c|}{ Modelos de Cidade } & \multicolumn{1}{|c}{ Característica } & \multicolumn{1}{c}{ Prática } \\
\hline Cidade Empresa & $\begin{array}{l}\text { Atratividade de investimentos } \\
\text { em um contexto de } \\
\text { competição global entre } \\
\text { cidades }\end{array}$ & $\begin{array}{l}\text { Fortalecimento da } \\
\text { produtividade e } \\
\text { fortalecimento das vantagens } \\
\text { competitivas }\end{array}$ \\
\hline $\begin{array}{l}\text { Cidade Energeticamente } \\
\text { Eficiente }\end{array}$ & $\begin{array}{l}\text { Extensão da racionalidade } \\
\text { econômica para o campo } \\
\text { ambiental e da eficiência } \\
\text { ecoenergética }\end{array}$ & $\begin{array}{l}\text { Redução do volume de } \\
\text { rejeitos e minimização dos } \\
\text { fluxos e da degradação } \\
\text { ambiental e energética }\end{array}$ \\
\hline Cidade de Políticas Públicas & $\begin{array}{l}\text { Equilíbrio entre a demanda } \\
\text { por serviços públicos, as } \\
\text { necessidades cotidianas da } \\
\text { população, e os investimentos } \\
\text { em redes e infra-estrutura }\end{array}$ & $\begin{array}{l}\text { Adaptação da oferta de } \\
\text { serviços públicos à } \\
\text { quantidade e qualidade } \\
\text { das demandas socia is }\end{array}$ \\
\hline
\end{tabular}

(30) ROSSI, p. 5.

(31) Cf. ACSELRAD, p. 79 a 89. 
Um exemplo dessa relação quase passional foi o episódio da visita de Burle Marx, durante a gestão da prefeita Telma de Souza, em 1989. Nessa oportunidade Burle Marx teceu uma crítica à pouca variedade de espécies, principalmente nativas, utilizadas ao longo dos $6 \mathrm{~km}$ de extensão dos jardins, resultando em certa monotonia. Essa crítica foi mal recebida pelos setores que temem qualquer intervenção nos jardins, gerando manifestações como a do agrônomo Domingos Tringali: "Respeito a autoridade de Burle Marx e acho que nossos jardins poderiam ser melhorados. Entretanto, não os considero monótonos. Ao contrário, na época de floração eles ficam maravilhosos, com espécies como a hemerocallis e o hibisco, apresentando cores diferentes a cada trecho." ${ }^{132}$

Sobre essa visita, a jornalista Lydia Federici declarou em sua coluna regular: "Aguardemos o projeto do grande paisagista. Prontos para aplaudir ou debater, em defesa da praia de Santos, pontos discutíveis. Para conservá-la ou torná-la mais caracteristicamente santista. ${ }^{\prime 33}$ Esta afirmativa demonstra o vínculo estabelecido entre a comunidade e os jardins, como uma identidade do santista, exacerbada por parcela da sociedade, de tal forma que o valor estético se subordina a esta identidade.

Essa relação se comprova quando, em pesquisa realizada pelo jornal A Tribuna em 1994, os jardins da praia foram citados por $40 \%$ dos entrevistados como a imagem que mais simboliza o "cartão-postal da cidade", entre outros 50 locais. Isso se dá, segundo o jornal, porque "Orla é motivo de orgulho", "Orgulho dos santistas, os jardins da orla da praia, com seus gramados, plantas e flores, têm uma relação profunda com a população local. Eles enfeitam, servem a passeios, reunião de amigos e à contemplação. Mais do que isso, são únicos. Nenhuma cidade litorânea do país possui jardins iguais, em extensão e largura." ${ }^{34}$

poder público, percebendo essa valorização, busca transformá-lo na própria imagem da cidade, buscando estender essa identidade local para um patamar mais amplo, ao querer torná-la referência nacional e internacional por meio de um processo também simbólico. Trata-se da tentativa de inclusão dos jardins da orla no Guiness book of records, na categoria de maior jardim de orla marítima do mundo ${ }^{35}$.

(32) Paisagistas iniciam debate sobre mudanças nos jardins. A Tribuna, set. 1989.

(33) Os novos jardins da praia. A Tribuna, 6 set. 1989.

(34) Jardins da praia são o cartão-postal da cidade. A Tribuna, 26 jan. 1994.

(35) Setur tenta incluir jardins no livro dos records. A Tribuna, 14 mar. 2000. 
No entanto, a questão da imagem da cidade e a qualidade do desenho urbano não pode se esgotar em seus aspectos simbólicos, formadores de uma identidade local, ao contrário, deve propiciar condições para que sua conformação espacial estabeleça parâmetros e diferenciais. Portanto, sob esse ponto de vista, o poder público não pode se omitir de promover um debate que vá além da questão meramente simbólica, assumindo um papel regulador nas questões que definem este aspecto, mas voltado também para a qualidade de vida, incluindo aí a própria identidade local, por meio de um projeto que demonstre claramente essa intenção.

Os jardins da orla de Santos constam no "repertório coletivo, na sua identidade e no imaginário da população santista" ${ }^{\prime 36}$. Por essa razão, concordamos que o poder público deve assumir junto à população a construção de uma imagem da cidade que valorize esse símbolo, ao mesmo tempo em que favoreça o desenvolvimento da cidade, buscando conjugar as diferentes necessidades e formas de apropriação da paisagem urbana de cada grupo social, por meio de um projeto o mais abrangente possível.

\section{Bibliografia}

ACSELRAD, Henri. Discursos da sustentabilidade urbana. Revista Brasileira de Estudos Urbanos e Regionais, n. 01, maio de 1999. Publicação semestral da Anpur - Associação Nacional de Pós-Graduação e Pesquisa em Planejamento Urbano e Regional.

ANDRADE, Carlos R. Monteiro. A peste e o plano. São Paulo, 1992. Dissertação (Mestrado) - Faculdade de Arquitetura e Urbanismo, Universidade de São Paulo.

. De Viena a Santos: Camillo Sitte e Saturnino de Brito, In: SITTE, Camilo. A construção das cidades segundo seus princípios artísticos. São Paulo: Ática, 1994.

ARAUJO Fo, J. R. A expansão urbana de Santos. In: A Baixada Santista. Aspectos geográficos. São Paulo: Edusp, 1964. v.3.

ARQUITETURA DA PAISAGEM - Repertório de Imagens, CD-ROM, Semiotc Systems. Concepção: Jonathas M. P. da Silva; Orient. Silvio Soares Macedo.

DEL RIO, Vicente. Introdução ao desenho urbano no processo de planejamento. São Paulo: Pini, 1990.

(36) Del Rio, p. 118. 
FICHER, Sylvia. Ensino e profissão - O curso de engenheiro arquiteto da Escola Politécnica de São Paulo. São Paulo, 1989. Tese (Doutorado) Faculdade de Filosofia, Letras e Ciências Humanas, Universidade de São Paulo.

FUNDAÇÃO ARQUIVO E MEMÓRIA DE SANTOS. Acervo de imagens e documentos.

GONÇALVES, Alcindo. Lutas e sonhos - Cultura política e hegemonia progressista em Santos, 1945 - 1962. São Paulo: Unesp, 1995.

GONTIER, Bernard. Santos. São Paulo: Mundo Impresso, 1991.

LEME, Gegê. Santos, jurado: A ilha e o novo. Santos: Prefeitura Munici$\mathrm{pal} /$ Prodesan, 1996.

MAIA, Prestes. Plano Regional de Santos. Santos: Tipografia Brasil, 1950.

PORTOCIDADE. Site - www. portocidade.stcecilia.br - Universidade Santa Cecília. Org. e Pesquisa: Luiz Antonio de Paula Nunes e Ana Kalassa El Banat. Coord. Áureo Pasqualeto Figueiredo e Antonio Salles Penteado.

ROSSI, Aldo. A arquitetura da cidade. São Paulo: Martins Fontes, 1995.

A TRIBUNA. $O$ aforamento de terrenos de marinha na praia da Barra. Santos, 8 maio 1921, p. 3.

Santos, 18 mar. 1921, p. 4.

Os progressos de Santos - Obras nas praias. Santos, 5 out. 1923, p. 2.

. Os progressos de Santos. Santos, 17 out. 1923, p. 2.

Santos. Santos, 24 mar. 1947, p. 5.

. Santos. Santos, 16 fev. 1950, p. 3.

. Santos. Santos, 4 jun. 1950.

. Praias de Santos. Santos, 23 maio 1973.

. Max de Sancti. Santos, 8 ago. 1976.

Lava-rápido e jardins. Em discussão na Câmara. Santos, 3

ago. 1976.

Obras na avenida da praia. Santos, 18 ago. 1981.

. O jardim João Moreira Salles. Santos, 24 jul. 1982.

1987.

. Diga não à destruição. Santos, artigos publicados em mar.

Chapéus-de-sol, a imagem símbolo. Santos, 27 ago. 1988.

. A praia de Santos. Santos, 6 set. 1989.

. Os novos jardins da praia. Santos, 6 set. 1989.

Paisagistas iniciam debate sobre mudança nos jardins.

Santos, set. 1989.

. Jardins da praia são o cartão-postal da cidade. Santos, 26

jan. 1994. 
A Tribuna. Todo cuidado é pouco para cuidar dos jardins. Santos, 26 jan. 1996, p. 17.

. MP vai acompanhar projeto de ciclovia na orla da praia. Santos, 4 jan. 1997.

Setur tenta incluir jardins no livro dos records. Santos, 14 mar. 2000. 